\title{
Collaboration with Japan could be more tempting
}

\section{A pilot scheme for postdocs, blending mobility with security, ought to be expanded.}

Sir - Your News story "Japan aims to forge stronger European links" (Nature $411,875 ; 2001)$ clearly identifies why it is difficult to recruit foreign scientists to work in Japan.

The Japan Society for the Promotion of Science (JSPS) has been running a pilot ' $2+2$ programme', which allows a British researcher to spend two years in Japan with the assurance of two years' subsequent funding in the United Kingdom. To promote greater collaboration between research in the European Union (EU) and Japan, this should now be established in other European countries. I would not have applied for this scheme without the return element, yet have already felt the benefits.

Researchers tempted by a period of research in Japan, or wishing to establish a long-term collaboration, face other problems in addition to those mentioned in your News story. Permanent university staff have heavy teaching loads which, combined with family commitments, allow only the fortunate to take long-term sabbaticals. Postdoctoral researchers are far more mobile (often not from choice). Schemes such as the $2+2$ programme can turn this mobility into a positive factor, helping them establish long-term collaborations early in their careers, while providing a degree of security.

Unfortunately, much may depend upon the Japanese economy. Provision under the JSPS scheme for Japanese language lessons has recently been reduced, and the tax-free salary status is under threat. Several other improvements could make a significant difference to the quality and number of applicants, for example one paid-for trip home during the two-year period, and greater opportunity for overseas research collaboration. Changes are also required in the host countries - I am unable to contribute to my university pension while in Japan, for example.

Other schemes for EU-Japanese collaboration should be open to all, unlike Britain's otherwise excellent Biotechnology and Biological Sciences Research Council (BBSRC) Japan Partnering Awards (http://www.bbsrc.ac.uk/international/ bbsrc/japan.html), which restricts applicants to current BBSRC grant holders or employees.

Although you report that in the past three years only two people have applied for JSPS funding from the EU, the JSPS does have other types of grant allotted for specific countries or institutions within Europe, and it expects to fund 440 fellowships for the financial year 2001 (see http://www.jsps.go.jp/e-home.htm). Angus Davison

Department of Ecology and Evolutionary Biology, Biological Institute, Tohoku University, AramakiAza-Aoba, Aoba-ku, Sendai 980 8578, Japan

\section{Could a website teach communication skills?}

Sir - The Opinion article "Learning to speak and write" (Nature 411, 1; 2001) points out that scientists need to be taught how to communicate the results of their research effectively; in Correspondence, D. A. Watson and his colleagues and M. Attrill (Nature 41 1, 992; 2001) refer to courses where this is being done.

Young scientists who do not have English as their first language are keenly aware of a further obstacle: the need to acquire these skills in English. Without them, many are media-shy and feel handicapped in effectively communicating the full significance and scope of their work, even if they have good science-communication skills in their native languages.

The Internet is changing the pace and practice of disseminating scientific information (Nature 410, 1023-1025; 2001), but the basic skills of scientific writing are still indispensable. To induce more young scientists to improve their scientific writing skills, the success story of the team running the web-based Journal of Young Investigators as discussed in your News Feature (Nature 411, 13-14; 2001) must be repeated by others, launching similar affordable Internet journals in other languages. This will go a long way in building the younger generation's confidence and skills.

In the absence of any formal training in scientific writing, it takes weeks or more for scientists to prepare their first few manuscripts in English. Publication will often be further delayed when journal editors ask for manuscripts to be rewritten. In an era when speed of communication is vital, the global scientific community needs a freely accessible website that will help people learn science-communication skills through home study, and assist them in evaluating the level of proficiency they are acquiring.

\section{Virendra K. Bhasin}

A. R. L. Teixeira's Chagas Disease Multidisciplinary Research Laboratory, Faculty of Medicine, University of Brasilia, Brasilia-DF, Brazil

\section{Curious effects created by reversal of colour}

Sir - The inadvertent reversal of Masaccio's Trinity (see above left for correct orientation) in my essay "Maintaining Masaccio" (Nature 412, 382; 2001) made nonsense of my point about the relationship between the asymmetrical composition and the off-centre approach by the spectator, but the error may yet be turned to good account.

As Leonardo da Vinci recognized, reversing a composition can make it look very different and even 'wrong': "When you are painting, you ought to have by you a flat mirror in which you should often look at your work ... [I]t will seem to be by
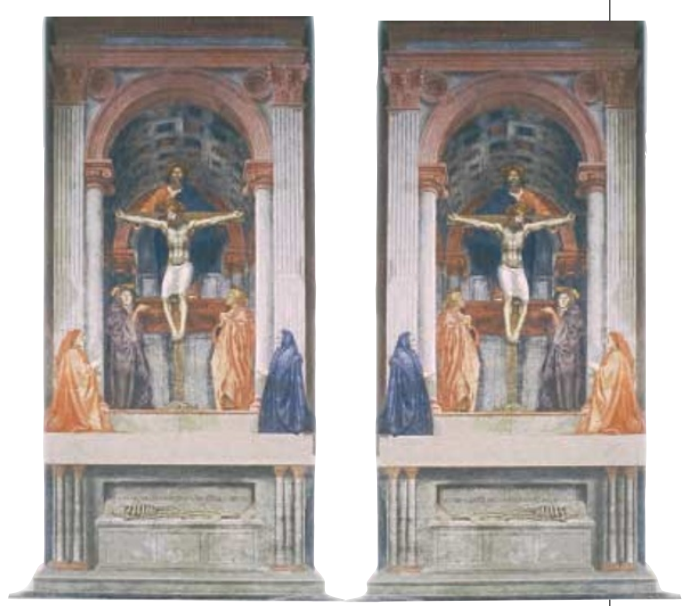

Shades of meaning: does the placing of colours give a clue that left is right and right is wrong?

the hand of another master and thereby you will better judge its faults."

This property of a reversed image has been widely recognized, with respect to the arrangement of forms, but it occurs to me, looking at the flipped Trinity, that colour might also be involved. Masaccio's carefully orchestrated asymmetries of red and blue look distinctly uncomfortable in reverse. Is this just a question of familiarity, or is there a 'handedness' in colour distribution as well as in composition?

Martin Kemp

Department of the History of Art,

University of Oxford, 59 George Street,

Oxford OX1 2BE, UK 